\title{
C-reactive protein levels and clinically important predictive outcomes in stable COPD patients
}

\author{
J.P. de Torres*, E. Cordoba-Lanus*, C. López-Aguilar*, M. Muros de Fuentes*, \\ A. Montejo de Garcini*, A. Aguirre-Jaime*, B.R. Celli ${ }^{\star}$ and C. Casanova*
}

ABSTRACT: The aim of this study was to determine the relationship between C-reactive protein (CRP) levels and factors known to predict outcome in stable chronic obstructive pulmonary disease (COPD) patients.

The following were studied in 130 stable COPD patients: spirometry, lung volume, arterial oxygen tension $\left(\mathrm{Pa}_{\mathrm{O}} \mathrm{O}_{2}\right)$, dyspnoea, 6-min walk distance (6MWD), body mass index, fat-free mass index, BODE (body mass index, obstruction, dyspnoea and exercise capacity), health-related quality of life, smoking status, the presence of cardiovascular risk factors or disease, corticosteroid use and number of exacerbations in the previous year. CRP levels were measured in these patients and in 65 controls. Using univariate and multivariate analyses, any possible association with the predictors of outcomes was evaluated.

CRP levels were higher in COPD patients than in controls (4.1 versus $1.8 \mathrm{mg} \cdot \mathrm{L}^{-1}$, respectively). Correlation was found with the following variables: forced expiratory volume in one second (FEV 1 ; -0.23), FEV1 \% (-0.20), forced vital capacity (FVC; -0.24), FVC \% (-0.24), Global Initiative for Chronic Obstructive Lung Disease stage (0.17), BODE (0.17), inspiratory capacity/total lung capacity (-0.20), $\mathrm{Pa}, \mathrm{O}_{2}(-0.40)$ and 6MWD (-0.30). Using multivariate analysis, $\mathrm{Pa}, \mathrm{O}_{2}$ and 6MWD manifested the strongest negative association with CRP levels.

C-reactive protein levels in stable chronic obstructive pulmonary disease patients are best correlated with arterial oxygen tension and 6-min walk distance. This should be considered when C-reactive protein levels are measured in stable chronic obstructive pulmonary disease patients.

KEYWORDS: Chronic obstructive pulmonary disease, C-reactive protein, systemic inflammation

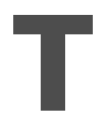
he American Thoracic Society/European Respiratory Society consensus states that: "Although COPD [chronic obstructive pulmonary disease] affects the lungs, it also produces significant systemic consequences" [1] These consequences can be detected clinically [2] and appear to be associated with the presence of systemic inflammatory markers [3].

C-reactive protein (CRP) is an acute-phase protein synthesised predominantly by the hepatocytes in response to tissue damage or inflammation. It reflects the total systemic burden of inflammation of individuals [4] and has been shown to be increased in COPD in stable condition [3] and during exacerbations [5]. It is also a predictor of hospitalisation and mortality in patients with chronic respiratory failure [6] CRP is higher in patients with poor forced

For Editorial comments see pages 874 and 877 . expiratory volume in one second (FEV1) and in those who smoke [7]. Finally, elevated levels of CRP seem to predict cardiovascular risk in patients with COPD [8] and can decrease with inhaled and systemic corticosteroids [9], oral statin therapy [10] and exercise [11].

It is widely accepted that CRP levels relate to the presence of airflow obstruction [12]. However, there are no studies that evaluate the relationship between CRP levels and other clinical variables known to predict outcome in patients with COPD. As CRP is used as a prognostic cardiovascular factor in the general population and particularly in COPD, this study aims to measure how prognostic factors of the disease affect CRP levels in stable patients, independently from the degree of airflow obstruction.

\section{METHODS}

The current study recruited COPD patients attending a pulmonary clinic from January 2000

\section{AFFILIATIONS}

${ }^{*}$ Respiratory Research Unit, and

"Biochemical Analysis Dept, Hospital Nuestra Señora de

Candelaria, Tenerife, Spain.

"Pulmonary and Critical Care

Division, St. Elizabeth's Medical

Center, Boston, MA, USA.

CORRESPONDENCE

J.P. de Torres

Unidad de Investigación

Hospital Nuestra Señora de

Candelaria

Ctra del Rosario s/n

38010 Santa Cruz de Tenerife

Canary Islands

Spain

Fax: 34922600562

E-mail: jupa65@hotmail.com

Received:

September 192005

Accepted after revision:

January 032006

SUPPORT STATEMENT

This study was partially funded by the Canarian Research and Health

Foundation (FUNCIS). 
to December 2004. Patients with all levels of airflow severity were consecutively included if they had smoked $\geqslant 20$ pack-yrs and had a post-bronchodilator FEV1/forced vital capacity (FVC) $<0.7$ after $400 \mu \mathrm{g}$ of inhaled albuterol. Patients were excluded if: they had a history of asthma and/or their FEV1 increased more than $12 \%$ or $200 \mathrm{~mL}$ after bronchodilation; or they had bronchiectasis, tuberculosis or other confounding inflammatory diseases, such as malignancy, arthritis, connective tissue disorders or inflammatory bowel disease. Patients were clinically stable (no exacerbation for 2 months) at the time of evaluation and were a sub-sample of those studied in the BODE (body mass index, obstruction, dyspnoea and exercise capacity) international multicentre study [13]. The Ethical Committee of the Hospital Nuestra Señora de Candelaria (Tenerife, Spain) approved the study and all participants gave written informed consent.

The following variables, which are known to predict outcome in COPD, were evaluated: age; dyspnoea, assessed by the Modified Medical Research Council (MMRC) scale [14]; degree of airflow obstruction, via FEV1; arterial oxygen tension $\left(\mathrm{Pa}_{\mathrm{a}} \mathrm{O}_{2}\right)$ [15]; exercise capacity, using 6-min walk distance (6MWD) [16]; lung hyperinflation, as expressed by the inspiratory capacity (IC) to total lung capacity (TLC) ratio [17]; body mass index (BMI) [18]; fat-free mass index (FFMI) [19]; BODE index [13]; and health-related quality of life, using the Saint George's Respiratory Questionnaire (SGRQ) [20]. The current authors registered the presence of cardiovascular risk factors (hypertension, diabetes, hypercholesterolaemia) or diagnosed cardiovascular disease (coronary artery, peripheral vascular or cerebrovascular disease), as well as the number of exacerbations in the previous year. It was also noted whether patients were actively smoking and whether they used corticosteroid (inhaled or systemic) therapy.

Post-bronchodilator FEV1, FVC, FEV1/FVC and IC/TLC were determined using a Jaegger 920 MasterLab $_{\circledR}$ spirometer and Body Box (both Masterlab, Jaegger, Würzburg, Germany), along with the European Community for Steel and Coal guidelines [21] to determine predicted values. BMI was calculated as the weight in $\mathrm{kg}$ divided by height in $\mathrm{m}^{2}$. FFMI was determined using the bioelectrical impedance Bodystat (Bodystat Ltd, Isle of Man, UK), dividing the fat-free mass weight in $\mathrm{kg}$ by the height in $\mathrm{m}^{2}$. Exacerbations were defined using the criteria developed by RODRIGUEZ-ROISIN [22].

Blood samples for CRP measurement were taken after $4 \mathrm{~h}$ of fasting, at the same time of the day $(08: 00 \mathrm{~h})$. Measurement was performed using a high-sensitivity CRP assay (latex) HS (measurement range $0.1-20 \mathrm{mg} \cdot \mathrm{L}^{-1}$; Roche Diagnostics, Indianapolis, MN, USA).

\section{Statistical analysis}

Variables are presented as a percentage, mean \pm SD or median (25th-75th percentile) depending on their distribution. Because of the non-normal distribution of CRP values, logarithmic transformation was used to perform parametric testing. An exploratory factor analysis was then performed for all variables including CRP to obtain its clustering in relatively independent dimensions. To explore differences in log CRP levels between healthy, ex-smoking COPD patients and smoking COPD patients, ANOVA analysis was performed, followed by a Scheffé test to compare the difference between each category. In order to study the differences in log CRP levels between healthy controls and COPD patients, females and males, those taking and not taking corticosteroids, those with and without cardiovascular risk factors or disease and patients who were current smokers versus nonsmoking patients, a univariate ANOVA test was applied with $95 \%$ confidence intervals (CI) for the estimation of differences. The correlations between log CRP levels and the different numerical variables were estimated using Pearson's or Spearman's linear bivariate correlation coefficient depending on the distribution of the second variable. Finally, a linear regression analysis was performed using the backward criterion strategy with log CRP as a dependent variable and variables that significantly correlated with log CRP levels as explanatory variables. A p-value $\leqslant 0.05$ was considered statistically significant in all analyses.

\section{RESULTS}

A total of 150 consecutive Caucasian patients (95 males) were recruited into the study. Of these patients, 20 patients (12 males) refused to participate in the study. Also recruited into the study were 65 healthy, nonsmoking subjects (32 males) from the general population, of similar age (mean \pm SD $65 \pm 11$, $p>0.05)$ and location. The clinical and physiological characteristics of the COPD patients are presented in table 1. Most of the patients were in Global Initiative for Chronic Obstructive Lung Disease (GOLD) stages II and III, $44 \%$ of them were still smoking, $55 \%$ had cardiovascular risk factors or disease and most of them $(77 \%)$ were on inhaled corticosteroid therapy.

Factor analysis showed that the variables conformed in five different areas: 1) BODE, FEV1, FVC, GOLD stage, IC/TLC, MMRC, 6MWD and $\mathrm{Pa}_{2} \mathrm{O}_{2} ; 2$ ) SGRQ, age, diffusing capacity of the lung for carbon monoxide, Charlson index, smoking status and pack-yr history; 3) cardiovascular risk factors or disease and exacerbations; 4) BMI; and 5) CRP and corticosteroid use.

CRP levels were higher in COPD patients than controls (4.1 versus $1.8 \mathrm{mg} \cdot \mathrm{L}^{-1}$, respectively, $\left.\mathrm{p}<0.001\right)$. Log CRP was not equal between controls, ex-smoking COPD patients and smoking COPD patients $(0.34 \pm 0.3$ versus $0.52 \pm 0.3$ versus $0.70 \pm 0.4$, respectively, overall ANOVA p-value <0.001). Further differences were found between: controls and exsmoking COPD patients (Scheffé p-value $<0.001$ ); controls and smoking COPD patients (Scheffé p-value $<0.001$ ); and ex-smoking and smoking COPD patients (Scheffé p-value $<0.001)$. Actual CRP levels are shown in figure 1. Comparisons of $\log \mathrm{CRP}$ levels adjusted for $\mathrm{Pa}_{2} \mathrm{O}_{2}, 6 \mathrm{MWD}, \mathrm{FEV} 1 \%$, IC/TLC and $\mathrm{BMI}$ did not reach statistical significance for sex $(95 \% \mathrm{CI}$ $-0.16-0.16, \quad \mathrm{p}=0.29)$, smoking status (95\% CI $-0.12-0.19$, $\mathrm{p}=0.81)$, corticosteroid use $(95 \% \mathrm{CI}-0.14-0.22, \mathrm{p}=0.19)$ or the presence of cardiovascular risk factors or disease $(95 \% \mathrm{CI}$ $-0.14-0.16, \mathrm{p}=0.39$ ).

Table 2 shows the correlation coefficients of log CRP levels with COPD prognostic factors. Statistically significant correlation, at the $\mathrm{p}<0.05$ level, was found with FEV1, FEV1 \%, FVC, FVC \%, IC/TLC, $\mathrm{Pa}_{2} \mathrm{O}_{2}$ and 6MWD. The results of a multivariate linear regression analysis are shown in table 3. $\mathrm{Pa}, \mathrm{O}_{2}$ and $6 \mathrm{MWD}$, and not the lung function indices, were the best explanatory factors of $\log$ CRP levels. 


\begin{tabular}{|c|c|c|}
\hline $\begin{array}{l}\text { Clinical and physiological } \\
\text { parameters }\end{array}$ & Subjects $n$ & Values \\
\hline Age yrs & 130 & $65 \pm 10$ \\
\hline FEV $1 \%$ pred & 128 & $53 \pm 21$ \\
\hline FVC \% pred & 128 & $83 \pm 23$ \\
\hline IC/TLC $<0.25 \%$ of patients & 128 & 25 \\
\hline GOLD stage $\%$ of patients & 128 & \\
\hline 1 & & 14 \\
\hline$\|$ & & 39 \\
\hline III & & 32 \\
\hline IV & & 15 \\
\hline 6MWD m & 126 & $459 \pm 99$ \\
\hline MMRC scale $>2 \%$ of patients & 130 & 14 \\
\hline BMI $\mathbf{k g} \cdot \mathbf{m}^{-2}$ & 130 & $17 \pm 3$ \\
\hline FFMI $\mathbf{k g} \cdot \mathrm{m}^{-2}$ & 130 & $27 \pm 5$ \\
\hline${\mathrm{Pa}, \mathrm{O}_{2}}_{\mathrm{mmHg}}$ & 127 & $71 \pm 11$ \\
\hline BODE points & 125 & $2(1-3)$ \\
\hline SGRQ total points & 126 & $34 \pm 19$ \\
\hline $\begin{array}{l}\text { Exacerbations times in the last } \\
\text { year }\end{array}$ & 130 & $1(0-2)$ \\
\hline Active smoking $\%$ of patients & 130 & 44 \\
\hline $\begin{array}{l}\text { Use of corticosteroids \% of } \\
\text { patients }\end{array}$ & 130 & 77 \\
\hline $\begin{array}{l}\text { Presence of cardiovascular risk } \\
\text { factors or disease \% of } \\
\text { patients }\end{array}$ & 130 & 55 \\
\hline
\end{tabular}

Data are presented as mean $\pm \mathrm{SD}, \%$ and median (25th-75th percentiles), unless otherwise stated. FEV1: forced expiratory volume in one second; FVC: forced vital capacity; IC: inspiratory capacity; TLC: total lung capacity; GOLD: Global Initiative for Chronic Obstructive Lung Disease; 6MWD: 6-min walk distance; MMRC: Modified Medical Research Council; BMI: body mass index; FFMl: fat-free mass index; $\mathrm{Pa}_{\mathrm{a}} \mathrm{O}_{2}$ : arterial oxygen tension; $\mathrm{BODE}$ : body mass index, obstruction, dyspnoea and exercise capacity; SGRQ: Saint George's Respiratory Questionnaire. $1 \mathrm{mmHg}=0.133 \mathrm{kPa}$

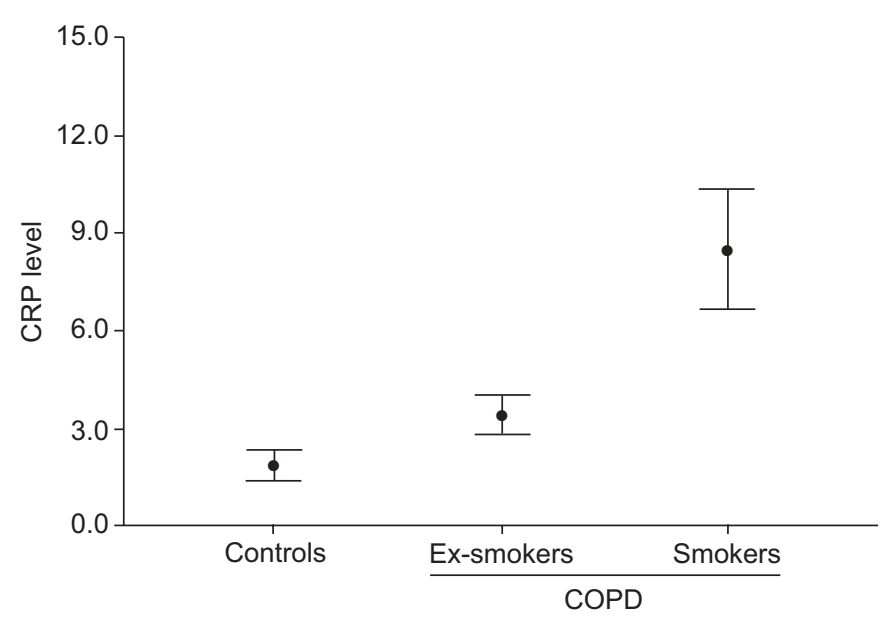

FIGURE 1. Data are presented as mean and $95 \%$ confidence intervals of Creactive protein (CRP) levels for controls, ex-smoking chronic obstructive pulmonary disease (COPD) patients and smoking COPD patients.
TABLE 2 Parameters that significantly correlated with log CRP levels

\begin{tabular}{lcc} 
Variable & Correlation & p-value \\
\hline Pa, $\mathbf{O}_{2}$ & -0.40 & $<0.001$ \\
6MWD & -0.30 & 0.001 \\
FVC & -0.24 & 0.006 \\
FVC $\%$ & -0.24 & 0.006 \\
FEV 1 & -0.23 & 0.008 \\
FEV $1 \%$ & -0.20 & 0.031 \\
GOLD & 0.18 & 0.042 \\
IC/TLC & -0.18 & 0.041 \\
BODE & 0.17 & 0.050 \\
BMI & 0.17 & 0.050 \\
\hline
\end{tabular}

Correlations were found using Pearson's bivariate linear correlation coefficient. $\mathrm{Pa}_{1} \mathrm{O}_{2}$ : arterial oxygen tension; 6MWD: 6-min walk distance; FVC: forced vital capacity; FEV1: forced expiratory volume in one second; GOLD: Global Initiative for Chronic Obstructive Lung Disease; IC: inspiratory capacity; TLC: total lung capacity; BODE: body mass index, obstruction, dyspnoea and exercise capacity; BMI: body mass index.

TABLE 3 Results of multivariate linear regression analysis ${ }^{\#}$

\begin{tabular}{lrcccc}
$\begin{array}{l}\text { Predictive } \\
\text { parameter }\end{array}$ & \multicolumn{4}{c}{ Regression coefficient } & p-value \\
\cline { 2 - 5 } & Value & SEM & 95\% Cl & Standardised & \\
\hline${\text { Pa, } \mathbf{O}_{\mathbf{2}}}$ & -0.011 & 0.004 & $-0.18--0.004$ & -0.271 & 0.003 \\
6MWD & -0.001 & 0.001 & $-0.002--0.001$ & -0.206 & 0.048 \\
FEV $\mathbf{1} \%$ & 0.006 & 0.008 & $-0.010-0.023$ & 0.298 & 0.457 \\
FVC \% & -0.008 & 0.005 & $-0.18-0.003$ & -0.395 & 0.142 \\
GOLD & -0.015 & 0.125 & $-0.263-0.233$ & -0.031 & 0.905 \\
IC/TLC & 0.051 & 0.703 & $-1.340-1.442$ & 0.010 & 0.942 \\
BODE & -0.022 & 0.037 & $-0.096-0.051$ & -0.103 & 0.549 \\
BMI & 0.006 & 0.008 & $-0.010-0.023$ & 0.075 & 0.465 \\
\hline
\end{tabular}

$\mathrm{Cl}$ : confidence interval; $\mathrm{Pa}_{\mathrm{a}} \mathrm{O}_{2}$ : arterial oxygen tension; 6MWD: 6-min walk distance; FEV1: forced expiratory volume in one second; FVC: forced vital capacity; GOLD: Global Initiative for Chronic Obstructive Lung Disease; IC: inspiratory capacity; TLC: total lung capacity; BODE: body mass index, obstruction, dyspnoea and exercise capacity; BMl: body mass index. ${ }^{\#}$ : with log C-reactive protein as a dependent variable, using the variables which showed significant correlations in the univariate analysis.

\section{DISCUSSION}

This is the largest clinical study investigating the influence of predictive outcomes on CRP levels in a well-defined population of stable COPD patients. The main and novel finding of this study is that CRP levels in stable COPD patients are most strongly associated with $\mathrm{Pa}_{\mathrm{a}} \mathrm{O}_{2}$ and 6MWD. The study also found that CRP levels correlated independently with other important prognostic clinical variables: FEV1, FVC, IC/TLC, GOLD stage and BODE index.

There is now sufficient evidence to support the presence of "extra-pulmonary or systemic" consequences of COPD that 
can be detected clinically [2] and that could also be measured by the determination and level of increased systemic inflammatory markers [3]. CRP is one of these markers. It is an acutephase protein synthesised predominantly by the hepatocytes in response to tissue damage or inflammation reflecting the total systemic burden of inflammation of individuals [4]. GAN and co-workers [3, 7] were the first to note the importance of high CRP levels in COPD patients. They showed that CRP is elevated in patients who actively smoked, had reduced lung function [7] or stable COPD [3]. They also demonstrated that in patients with COPD, CRP levels predicted cardiovascular mortality [8] and decreased with treatment with inhaled fluticasone [9]. Other researchers have shown that: patients with COPD have higher levels of CRP, independent of cardiovascular risk factors [12]; CRP predicts mortality in patients with chronic respiratory failure [6]; and CRP levels decrease with exercise [11] and pharmacological therapy with statins [10]. Recently, BROEKHUIZEN et al. [23] found that highsensitivity CRP was a marker of impaired energy metabolism, functional capacity and distress in 102 severe COPD patients.

In the present study's population of stable COPD patients, CRP levels correlated mainly with physiological parameters, such as FEV1, FVC, IC/TLC, 6MWD, $\mathrm{Pa}_{2} \mathrm{O}_{2}$ and $\mathrm{BMI}$, or others that include them as BODE index or GOLD stages. In the factor analysis, unsurprisingly, most of these variables were clustered in the same group. In contrast, CRP was grouped with corticosteroids. This could mean that CRP represents a different aspect of COPD (the inflammatory one) associated with these important outcomes, and which is (as the available data support) directly affected by corticosteroid therapy [9].

The present study confirms the existing data, supporting the fact that when lung function worsens, CRP levels increase [7]. This could also explain the direct relationship found between CRP levels and GOLD stages or the BODE index, which includes some of the previously mentioned outcomes parameters (FEV1, 6MWD and BMI).

One of the most important and novel findings of the current study is the inverse correlation between CRP levels and $\mathrm{Pa}, \mathrm{O}_{2}$. This interesting finding requires further research. Indeed, it is widely accepted that COPD patients with hypoxaemia have a higher mortality, which is improved with oxygen therapy. Hypoxaemia triggers oxidative stress and inflammation in COPD patients [24]. Unfortunately, until now, no data have proved that oxygen therapy decreases systemic inflammation in stable COPD patients. The association observed in the present study supports the need for more extensive exploration of the relationship between oxygenation, inflammatory markers and outcomes.

It was also observed that CRP levels inversely correlated with 6MWD. KoECHLIN et al. [25] found that CRP levels inversely correlated with endurance time. BROEKHUIZEN et al. [23] also found that CRP increases in patients with poor exercise capacity. Indeed, some authors postulate that the skeletal muscle dysfunction is a direct consequence of the systemic effects of the disease [26], whereas others propose that the "myopathy" is an independent process that contributes to the systemic inflammatory load of the disease [27]. Whatever the mechanism, the present results indicate that measuring
CRP levels in stable conditions could indirectly reflect the exercise capacity of these patients, an important prognostic factor of the disease.

The present authors are the first to report an inverse correlation between lung hyperinflation as determined by the IC/TLC ratio and circulating CRP levels. Recently, CASANOVA et al. [17] demonstrated that lower values of IC/TLC are associated with worse survival. OGA et al. [28] also showed that as lung hyperinflation worsens, exercise capacity decreases over time. The present study indicates that as hyperinflation worsens, the CRP levels increase. It may be that the hyperinflated state is not associated with "burned out" inflammation but rather with an active inflammatory process of which elevated CRP is a good marker. Indeed, the concept of persistent inflammation is supported by the findings of HoGG et al. [29] who described intense inflammatory changes in the lung and airways of patients with severe emphysematous COPD, who underwent lung volume-reduction surgery and had a long-standing history of smoking abstinence. Whether the CRP level is only a marker or an active component of the inflammatory process remains to be explored.

Interestingly, in the present study, BMI correlated directly with CRP. This contrasts with the only published study relating CRP and BMI, in which SCHOLS et al. [30] observed high CRP levels in a special subset of 16 COPD patients with high resting energy expenditure and low FFMI. In the present much larger set of COPD patients with different degrees of obstruction and $\mathrm{BMI}$, the BMI and CRP levels displayed a direct correlation. This could imply that different inflammatory markers, such as tumour necrosis factor- $\alpha$ and CRP, have different behaviour, relating to malnutrition or perhaps reflecting depletion of different compartments (FFMI versus fat mass, respectively). More studies are needed to help resolve these controversial findings.

The current authors' work duplicates the previous findings of higher CRP levels in smoking COPD patients compared with nonsmoking COPD patients [7]. Unfortunately, this effect could not be confirmed in the control group because only nonsmoking individuals were recruited to represent the "normal" population. However, the level of CRP in the exsmoking COPD population remained significantly higher than the nonsmoking control group. This finding is consistent with the theory that once initiated the inflammatory state seems to persist, albeit at a seemingly lower level. Conversely, it provides us with a strong argument to develop and institute therapies aimed at decreasing the inflammatory state independent of smoking cessation.

This study has several limitations. First, even though patients taking steroids had lower CRP levels than those who did not, this difference was not statistically significant. This might be due to the small sample size with low statistical power and sensitivity or it could be because the patients were not in a trial and the compliance of medication use was unreliable. In addition, several corticosteroid preparations were used and their effect on CRP is unknown. Secondly, patients with cardiovascular risk factors or diagnosed disease did not have higher CRP levels. This contradictory finding cannot be explained, and the present authors did not formally evaluate 
the presence of active cardiovascular disease but depended solely on the clinical information recorded. Likewise, the patients were not prospectively followed to determine the occurrence of new cardiac events.

In summary, the present study confirms that $\mathrm{C}$-reactive protein levels are higher in stable chronic obstructive pulmonary disease patients. C-reactive protein levels are associated with important clinical variables that help predict patient outcome independently of the degree of airflow obstruction. Of these, the most important were the arterial oxygen tension and 6-min walk distance. This reinforces and supports the relevance of Creactive protein measurement and the information presented here should be considered when C-reactive protein levels are measured in stable chronic obstructive pulmonary disease patients. Further follow-up cohort studies with bigger samples and that measure C-reactive protein levels prospectively should help determine the validity of these findings.

\section{ACKNOWLEDGEMENTS}

The authors would like to thank J. Villlar for his invaluable contribution to the completion of this project.

\section{REFERENCES}

1 Celli BR, MacNee W. ATS/ERS Task Force. Standards for the diagnosis and treatment of patients with COPD: a summary of the ATS/ERS position paper. Eur Respir J 2004; 23: 932-946.

2 Agustí AGN, Noguera A, Sauleda J, Sala E, Pons J, Busquets $X$. Systemic effects of chronic obstructive pulmonary disease. Eur Respir J 2003; 21: 347-360.

3 Gan WQ, Man SFP, Senthilselvan A, Sin DD. Association between chronic obstructive pulmonary disease and systemic inflammation: a systematic review and metaanalysis. Thorax 2004; 59: 574-580.

4 Pepys MB, Hirschfield GM. C-reactive protein: a critical update. J Clin Invest 2003; 111: 1805-1812.

5 Malo O, Sauleda J, Busquets X, Miralles C, Agusti AG, Noguera A. Systemic inflammation during exacerbations of chronic obstructive pulmonary disease. Arch Bronconeumol 2002; 38: 172-176.

6 Cano NJM, Pichard C, Roth H, et al. C-reactive protein and body mass index predict outcome in end-stage respiratory failure. Chest 2004; 126: 540-546.

7 Gan WQ, Paul Man SF, Sin DD. The interactions between cigarette smoking and reduced lung function on systemic inflammation. Chest 2005; 127: 558-564.

8 Sin DD, Paul Man SF. Why are patients with chronic obstructive pulmonary disease at increased risk of cardiovascular disease? The potential role of systemic inflammation in chronic obstructive pulmonary disease. Circulation 2003; 107: 1514-1519.

9 Sin DD, Lacy P, York E, Paul Man SF. Effects of fluticasone on systemic markers of inflammation in chronic obstructive pulmonary disease. Am J Respir Crit Care Med 2004; 170: 760-765.

10 Albert MA, Danielson E, Rifai N, Ridker PM, for the PRINCE investigators. Effects of statin therapy on Creactive protein levels. The pravastatin inflammatory/CRP
Evaluation (PRINCE): a randomized trial and cohort study. JAMA 2001; 286: 64-70.

11 Ford ES. Does exercise reduce inflammation? Physical activity and C-reactive protein among U.S. adults. Epidemiology 2002; 357: 763-767.

12 Pinto Plata VM, Mullerova $\mathrm{H}$, Toso JF, et al. C-reactive protein in patients with COPD, control smokers, and nonsmokers. Thorax 2006; 61: 23-28.

13 Celli BR, Cote CG, Marin JM, et al. The body mass index, airflow obstruction, dyspnea and exercise capacity index in chronic obstructive pulmonary disease. N Engl J Med 2004; 350: 1005-1012.

14 Nishimura K, Izumi T, Tsukino M, Oga T. Dyspnea is a better predictor of 5-year survival than airway obstruction in patients with COPD. Chest 2002; 121: 1434-1440.

15 Gerardi DA, Lovett L, Benoit-Connors ML, Reardon JZ, ZuWallack RL. Variables related to increased mortality following out-patient pulmonary rehabilitation. Eur Respir J 1996; 9: 431-435.

16 Pinto-Plata VM, Cote C, Cabral H, Taylor J, Celli BR. The 6min walk distance: change over time and value as a predictor of survival in severe COPD. Eur Respir J 2004; 23: 28-33.

17 Casanova C, Cote C, de Torres JP, et al. The inspiratory to total lung capacity ratio predicts mortality in patients with COPD. Am J Respir Crit Care Med 2004; 171: 591-597.

18 Schols AM, Slagen J, Volovics L, Wouters EF. Weight loss is a reversible factor in the prognosis of chronic obstructive pulmonary disease. Am J Respir Crit Care Med 1998; 15: 1791-1797.

19 Schols A. Nutrition in chronic obstructive pulmonary disease. Curr Opin Pulm Med 2000; 6: 110-115.

20 Domingo-Salvany A, Lamarca R, Ferrer M, et al. Healthrelated quality of life and mortality in male patients with chronic obstructive pulmonary disease. Am J Respir Crit Care Med 2002; 166: 680-685.

21 Quanjer PH. Standarized lung function testing. Report of the Working Party for the European Community for Steel and Coal. Bull Eur Physiopath Respir 1983; 19: Suppl. 5, 22-27.

22 Rodriguez-Roisin R. Toward a consensus definition for COPD exacerbations. Chest 2000; 117: Suppl. 2, 398S-401S.

23 Broekhuizen R, Wouters EF, Creutzberg EC, Schols AM. Raised CRP levels mark metabolic and functional impairment in advanced COPD. Thorax 2006; 61: 17-22.

24 Snider GL. Understanding inflammation in chronic obstructive pulmonary disease: the process begins. Am J Respir Crit Care Med 2003; 167: 1045-1046.

25 Koechlin C, Couillard A, Cristol JP, et al. Does systemic inflammation trigger local exercise-induced oxidative stress in COPD? Eur Respir J 2004; 23: 538-544.

26 Barnes PJ, Shapiro SD, Pauwels RA. Chronic obstructive pulmonary disease: molecular and cellular mechanisms. Eur Respir J 2003; 22: 672-688.

27 Maltais F. Skeletal muscles in chronic airflow obstruction: why bother? Am J Respir Crit Care Med 2003; 168: 916-917.

28 Oga $T$, Nishimura $K$, Tsukino $M$, Sato $S$, Hajiro $T$, Mishima M. Exercise capacity deterioration in patients 
with COPD: longitudinal evaluation over 5 years. Chest 2005; 128: 62-69.

29 Hogg JC, Chu F, Utokaparch S, et al. The nature of smallairway obstruction in chronic obstructive pulmonary disease. N Engl J Med 2004; 350: 2645-2653.
30 Schols AM, Buurman WA, Staal van den Brekel AJ, Dentener MA, Wouters EF. Evidence for a relation between metabolic derangements and increased levels of inflammatory mediators in a subgroup of patients with chronic obstructive pulmonary disease. Thorax 1996; 51: 819-824. 